\title{
Unspecified Non-communicable Diseases in Jamaica: Has the Time Come to Unravel this Label?
}

Bourne $\mathrm{PA}^{1 *}$, Francis $\mathrm{C}^{2}$, Sharpe-Pryce $\mathbf{C}^{3}$, Hudson-Davis $\mathrm{A}^{4}$, Solan $\mathrm{I}^{5}$, Watson-Coleman $\mathrm{O}^{6}$, Rhule $\mathrm{J}^{2}$, Clarke $\mathrm{J}^{2}$ and Campbell-Smith $\mathrm{J}^{7}$

${ }^{1}$ Socio-Medical Research Institute, Jamaica

2University of Technology, Jamaica

${ }^{3}$ Chair, Department of History, Northern Caribbean University, Mandeville, Jamaica

${ }^{4}$ Capella University, USA

${ }^{5}$ Department of Mathematics and Computer Science, South Carolina State University, USA

${ }^{6}$ Southern Connecticut State University, USA

${ }^{7}$ Cable and Wireless Jamaica Limited, Jamaica

"Corresponding author: Bourne PA, Socio-Medical Research Institute, Jamaica, Tel: 1876566 3088; E-mail: paulbourne1@yahoo.com, paulbourne1@gmail.com Rec Date: Mar 12, 2014, Acc Date: May 05, 2014, Pub Date: May 07, 2014

Copyright: ( 2014 Bourne PA, et al. This is an open-access article distributed under the terms of the Creative Commons Attribution License, which permits unrestricted use, distribution, and reproduction in any medium, provided the original author and source are credited.

\begin{abstract}
Introduction: In 2007, for the first time in Jamaica unspecified chronic Non-communicable Diseases (NCDs) became greater $(26.3 \%)$ than the listed NCDs (hypertension, 23.1\%; diabetes, 13.8\%; arthritis, $6.3 \%$ and chronic respiratory disease, $10.7 \%$ ). The time has come for scholars to unravel the unspecified NCDs.
\end{abstract}

Objectives: These are to evaluate unspecified chronic conditions, to provide a better understanding of whom and what constitutes this cohort, and make information available about the new unraveled unspecified NCDs in Jamaica.

Materials and methods: The dataset for 2007 Jamaica Survey of Living Conditions (JSLC) is used for this study. JSLC is a modification of the World Bank's Household Living Standards Survey. It is a national representative crosssectional survey that is conducted annually. The sample for this research is 234 respondents who were classified as having other NCDs. Chi-square, independent sample t-test, analysis of variance and logistic regression are used to analyse the data.

Findings: The majority of the respondents are females (56\%); $44 \%$ is in the wealthier classes; $37 \%$ in the poorer classes $(20.1 \%$ below the poverty line); $42 \%$ reported having at least good self-rated health status; $56 \%$ dwell in rural areas; $23 \%$ is less than 16 years of age; $22 \%$ is at least 60 years of age; $16.7 \%$ have diabetes and chronic respiratory disease, and $33.2 \%$ have arthritis.

Conclusion: This study provides the framework for a better understanding of those with unspecified chronic conditions and offers policy makers and others pertinent health information and insights that can be used to conceptualize new treatment options.

Keywords: Cardiovascular disease; Cerebrovascular disease; Chronic non-communicable disease; Unspecified chronic condition; Jamaica

\section{Introduction}

Chronic Non-communicable Diseases (NCDs) are the leading causes of human deaths globally [1-3]. In fact, statistics from the World Health Organization (WHO) revealed that in 2008 about 63 percent of all global deaths occurred due to NCDs and that 69.8 percent of that research is among people less than 70 years old [3]. Unlike the global statistics on total human deaths that are caused by NCDs, the figure in the low-to middle-income countries is 29 percent and 30 percent in the Americas [1,4]. Hospedales et al. [1] and Hennis et al. [5] speak to the NCDs epidemic in the English-speaking Caribbean region; when they claimed that this region has the highest death rates due to NCDs in the Americas. This demonstrates the health challenge of governments, public health specialists, health care practitioners and other people to address the matter of NCDs.
Jamaica, a country in the English-speaking Caribbean region, experienced an increase in NCDs and there is also a change in the identity of those that are faced with these conditions over the last ten years [6-11]. This reality is captured in a study conducted by Bourne et al. [7] that the rate of NCDs in Jamaica increased from 8 per 1,000 in 2002 to 56 per 1,000 in 2007. On disaggregating the NCDs for the studied period, the researchers found that the increase in diabetes was $185 \%$, hypertension, $12.7 \%$, and that 5 in every 100 diabetics are less than 30 years of age. Such data revealed the changing face of NCDs in Jamaica, which is vividly explained in a study on NCDs in Jamaican children less than 14 years of age [9]. The high prevalence of NCDs, description of who are involved, and the typology of the conditions are typically the same across the Caribbean $[1,4,12]$.

In a national cross-sectional probability survey of 2,848 Jamaicans ages 15-74 years old, Wilks et al. [11] found that 51.7 percent are either overweight or obese; 7.9 percent have diabetes mellitus; 25.2 percent indicated having hypertension; 35.3 percent are pre-hypertensive; 11.7 
percent have high cholesterol, and 25.6 percent experience depression. The dilemma of the situation is present in the statistics, which showed that 50.7 percent of hypertensive knew that they are compared to 76.1 percent of the diabetics and 14.0 percent of those with high cholesterol. The issue of a high undiagnosed diabetes rate is equally high in Cameroon, 80 percent [13], which speaks to another side to the NCDs epidemic discourse and highlights the challenges in effectively addressing the matter.

The NCDs epidemic in Jamaica, and by extension the wider low-tomiddle income nations, are even more intensified as Bourne et al's work [6], which revealed that hypertension and diabetes for the population of Jamaica ( $>0$ years old) are greater than of the population 15-74 years old, 33.3 percent and 19.9 percent respectively. The prevalence of hypertension and diabetes in Jamaica are greater than that, which is reported in the British Virgin Islands (i.e., Eastern Caribbean Islands); hypertension, 16.6 percent and diabetes, 10.0 percent [12]. The burden of NCDs in Jamaica is equally the same in Cameroon [13], British Virgin Islands [12], South Africa [14] and this extends to the rest of the world [15]. While NCDs such as heart diseases, diabetes, hypertension, neoplasm and stroke are the leading cause of deaths in the Caribbean [16], the results are no different in low-to middle-income developing nations $[2,3]$.

The Jamaica Survey of Living Conditions (JSLC) for Jamaica [17], which collects data on health indices, education, income and other socio-economic indicators for the government of Jamaica to aid planning, for years have been publishing data on NCDs, namely diabetes, hypertension, arthritis and unspecified conditions. A study by Bourne et al., which used data from the survey, found that the majority of respondents who reported NCDs are in the unspecified conditions category (37.8 percent) [6]. The prevalence rate in the unspecified NCDs categorization outweighs the classified ones such as hypertension (33.3 percent); diabetes (19.9 percent) and arthritis (9.0 percent) and this speaks to the lack of information that for decades marks how the planning process is fashioned and executed in Jamaica.

The reality is, assaults, cerebrovascular diseases, diabetes mellitus, cancers, heart diseases, lower respiratory diseases and hypertension are among the ten leading causes of deaths in Jamaica [18]. However, national data are only collected and published on diabetes, hypertension, arthritis and unspecified chronic conditions. With Bourne et al's work is showing that the unspecified NCDs constitute most of the self-reported diagnosed health conditions in Jamaica [6], many questions arise therefore, which are left unanswered by this categorization. While the classification by Wilks et al. work expand on that of the JSLC to include diabetes, hypertension, pre-hypertension, high cholesterol, depression, nutritional status and sickle cell disease [11]; there is still a gap in the literature and the unspecified categorization does not aid planning, but is rather is hindered by it.

The objectives of this study, therefore, are to evaluate unspecified chronic conditions, provide better understanding as to who and what constitutes this cohort, and furnished relevant information about the newly unraveled unspecified NCDs in Jamaica for the purpose of aiding planning. Reticence about NCDs will not enhance planning for these conditions and with Baldwin et al's claim that cardiovascular disease, neoplasm, diabetes and chronic respiratory diseases are likely to account for approximately 81 percent of all deaths in Latin America and the Caribbean, by 2030 [19]. In fact, ignorance in the unspecified NCDs group could significantly impact addressing the issue of epidemic. It is imperative, therefore, for us to unravel the unspecified
NCDs in Jamaica in order to make available to policy planners more germane information that can be included in the planning process.

\section{Materials and Methods}

\section{Analytical method}

The current study utilizes the dataset from the 2007 Jamaica Survey of Living Conditions (JSLC 2007) [20]. The JSLC's survey is conducted jointly by the Planning Institute of Jamaica (PIOJ) and the Statistical Institute of Jamaica (STATIN), which seeks to guide policy formulations [17]. The JSLC is a national cross-sectional descriptive survey, which is a modification of the World Bank's Living Standards Survey [21]. Data are collected using stratified random sampling techniques. The sample is weighted to reflect the population of Jamaica. The households in the JSLC are interviewed on an annual basis for a period of up to four years, after which a new representative sampling frame is redesign and drawn. A detailed presentation of the sampling techniques is in other published works $[22,23]$.

\section{Data}

The JSLC compiles data on households' characteristics, health, education, expenditure, social programmes, and other information. The survey results are gathered by using a standardized instrument (i.e., questionnaire) that on average takes approximately 45 minutes to complete by each respondent. For this study 234 respondents $(26.3$ percent) from the sample of the 2007 JSLC survey is used and the people are all those classified under the heading of having unspecified NCDs. The data are entered, stored and retrieved in the Statistical Packages for the Social Sciences (SPSS) for Windows, Version 21.0. For the purpose of the data analyses, the researchers used chi square, independent sample t-test, analysis of variance, logistic regression and percentages. A p-value $<5 \%$ is used to determine statistical significance of variables (i.e., $95 \%$ confidence interval).

\section{Definition of variables}

Health: This is defined as the self-rated health status of an individual.

Good health: Is a binary variable where $1=$ at least good self-rated health status and $0=$ otherwise.

Age: This is the total amount of time lived since birth, measured from one birthday to the next.

Age groups: Children are individual's ages 0 to 15 years old; young adults, 16-30 years; other aged adults, 31-59 years old; young-old, 60-74 years old; old-old, 75-84 years old-and oldest-old, 85+ years old.

Health-care seeking behavior (or visits to medical professional): This is derived from the question 'Have you sought medical attention in the last four weeks (using the survey period), where $1=$ yes and $0=$ otherwise.

Other NCDs: These include malignant neoplasm, ischaemic and other heart diseases, cerebrovascular diseases, chronic respiratory diseases, and high cholesterol.

Health insurance coverage: This is a binary measure, in which 1 denotes self-reported ownership of private and/or public health insurance coverage and 0 is otherwise. 
Citation: Bourne PA, Francis C, Sharpe-Pryce C, Hudson-Davis A, Solan I, et al. (2014) Unspecified Non-communicable Diseases in Jamaica: Has the Time Come to Unravel this Label?. J Trop Dis 2: 138. doi:10.4172/2329-891X.1000138

Page 3 of 10

Purchased prescribed medications: This individual reported information that he/she filled the prescription that he/she received on visit(s) to health care practitioner(s).

Health indices: For this paper, this concept is measured using illness (or self-reported illness), health-care seeking behavior (or health care utilization), health insurance coverage, health insurance utilization and number of visits to health care practitioner(s).

Americas: The landmass comprising of North, South, Central and the Caribbean.

\section{Results}

Table 1 presents information on the socio-demographic characteristics of the sampled population $(n=234)$. Twenty-two and three tenths percent of the respondents are $60+$ years old, with 23.1 percent being less than 15 years old and 18.4 percent young adults. The majority of the respondents are single people ( 60.9 percent), dwell in rural areas (55.6 percent), females (56.4 percent) and in the wealthy social class (43.5 percent). Comparatively, 20.1 percent of the respondents are below the poverty line and 20.9 percent are in the upper 20 percent; and 4.1 persons dwell in room (i.e. $4.1 \pm 2.3$ persons, 95\% CI: 3.7-4.4 persons).

\begin{tabular}{|c|c|c|}
\hline Detail & $\mathrm{n}$ & Percent \\
\hline \multicolumn{3}{|l|}{ Gender } \\
\hline Male & 102 & 43.6 \\
\hline Female & 132 & 56.4 \\
\hline \multicolumn{3}{|l|}{ Age group } \\
\hline Children & 54 & 23.1 \\
\hline Young adults & 43 & 18.4 \\
\hline Other aged adults & 85 & 36.3 \\
\hline Young old & 32 & 13.7 \\
\hline Old old & 13 & 5.6 \\
\hline Oldest old & 7 & 3.0 \\
\hline \multicolumn{3}{|l|}{ Marital status } \\
\hline Married & 51 & 28.5 \\
\hline Never married & 109 & 60.9 \\
\hline Divorced & 3 & 1.7 \\
\hline Widowed & 16 & 8.9 \\
\hline \multicolumn{3}{|l|}{ Income Quintile } \\
\hline 1 (below the poverty line - poorest $20 \%$ ) & 47 & 20.1 \\
\hline 2 (poor) & 39 & 16.7 \\
\hline 3 (middle) & 46 & 19.7 \\
\hline 4 (wealthy) & 53 & 22.6 \\
\hline 5 (wealthiest $20 \%$ ) & 49 & 20.9 \\
\hline \multicolumn{3}{|l|}{ Area of residence } \\
\hline Urban & 72 & 30.8 \\
\hline Peri-urban & 32 & 13.7 \\
\hline Rural & 130 & 55.6 \\
\hline Social assistance & & \\
\hline
\end{tabular}


Citation: Bourne PA, Francis C, Sharpe-Pryce C, Hudson-Davis A, Solan I, et al. (2014) Unspecified Non-communicable Diseases in Jamaica: Has the Time Come to Unravel this Label?. J Trop Dis 2: 138. doi:10.4172/2329-891X.1000138

Page 4 of 10

\begin{tabular}{|l|l|l|}
\hline Yes & 27 & 11.5 \\
\hline No & 207 & 88.5 \\
\hline Crowding, median (range) & $4.1 \pm 2.3$ people; $95 \%$ Cl: $3.7-4.4$ people \\
\hline
\end{tabular}

Table 1: Socio-demographic characteristics, $n=234$

Table 2 summarizes the health indices of sampled respondents. The majorities of the respondents do not have a health insurance policy (81.2 percent), reported having an illness (99.6 percent), and sought health care services (75 percent). About 41 percent of the sampled respondents indicate at least good health status, 49.4 percent utilize private health care facilities and the mean number of visits to health care professionals is $1.6 \pm 1.4$ visits, $95 \%$ CI: $1.3-1.8$ visits. The majority of those who attend private health care facilities purchase medications (82.8 percent) compared to 17.2 percent of those who attend public health care facilities.

\begin{tabular}{|c|c|c|}
\hline Detail & $\mathbf{n}$ & Percent \\
\hline \multicolumn{3}{|l|}{ Self-rated health status } \\
\hline Very good & 24 & 10.3 \\
\hline Good & 71 & 30.3 \\
\hline Fair & 83 & 35.5 \\
\hline Poor & 44 & 19.0 \\
\hline Very poor & 10 & 4.3 \\
\hline \multicolumn{3}{|l|}{ Health-care seeking behavior } \\
\hline Yes & 174 & 74.4 \\
\hline No & 58 & 25.0 \\
\hline \multicolumn{3}{|l|}{ Health insurance coverage } \\
\hline Private & 24 & 10.3 \\
\hline Public & 20 & 8.5 \\
\hline None & 190 & 81.2 \\
\hline \multicolumn{3}{|l|}{ Self-reported Illness } \\
\hline Yes & 232 & 99.6 \\
\hline No & 1 & 0.4 \\
\hline \multicolumn{3}{|l|}{ Purchased Medication based on } \\
\hline Attended Private health care facility & 144 & 82.8 \\
\hline Attended Public health care facility & 30 & 17.2 \\
\hline \multicolumn{3}{|l|}{ Health care utilization } \\
\hline Private & 86 & 49.4 \\
\hline Public & 88 & 50.6 \\
\hline Number of visits to health care practitioner(s) & \multicolumn{2}{|c|}{$1.6 \pm 1.4$ visits, $95 \% \mathrm{Cl}: 1.3-1.8$ visits } \\
\hline
\end{tabular}

Table 2: Health Indices, $\mathrm{n}=234$

Females sought more health care services (80.2 percent) than their male counterparts (68.3 percent), $\left.\chi^{2}=4.261, \mathrm{P}=0.039\right)$ as well as visited more frequently than males ( $\mathrm{t}$-statistics $=-2.54 ; 0.033$ ); and no statistical association existed between self-rated health status and gender $(\mathrm{P}=0.098)$ and between health insurance coverage and gender $(\mathrm{P}=0.564)$, (Table 3$)$. There is no statistical difference in the purchase health insurance coverage by the gender (male: private health 
Citation: Bourne PA, Francis C, Sharpe-Pryce C, Hudson-Davis A, Solan I, et al. (2014) Unspecified Non-communicable Diseases in Jamaica:

insurance coverage, 7.8 percent; female: 12.1 percent; $\chi^{2}=1.145$, $\mathrm{P}=0.564)$.

\begin{tabular}{|c|c|c|c|c|c|}
\hline \multirow[t]{3}{*}{ Detail } & \multicolumn{4}{|c|}{ Gender } & $x^{2} ; P$ value \\
\hline & \multicolumn{2}{|c|}{ Male, $n=102$} & \multicolumn{2}{|c|}{ Female, $n=132$} & \multirow[b]{3}{*}{$7.839 ; 0.098$} \\
\hline & $\mathbf{n}$ & percent & $\mathbf{n}$ & percent & \\
\hline Self-rated health status & & & & & \\
\hline Very good & 12 & 11.8 & 12 & 9.1 & \\
\hline Good & 32 & 31.4 & 39 & 29.5 & \\
\hline Fair & 27 & 26.5 & 56 & 42.4 & \\
\hline Poor & 24 & 23.5 & 21 & 16.0 & \\
\hline Very poor & 6 & 5.9 & 4 & 3.9 & \\
\hline Health-care seeking behavior & & & & & $4.261 ; 0.039$ \\
\hline Yes & 69 & 67.6 & 105 & 79.5 & \\
\hline No & 32 & 31.3 & 26 & 19.7 & \\
\hline Health insurance coverage & & & & & $1.145 ; 0.564$ \\
\hline Private & 8 & 7.8 & 16 & 12.1 & \\
\hline Public & 9 & 8.8 & 11 & 8.3 & \\
\hline None & 85 & 83.3 & 105 & 79.5 & \\
\hline No. of visits to health care practitioner & $\begin{array}{l}1.3 \\
95 \%\end{array}$ & & $\begin{array}{l}1.7 \\
95 \%\end{array}$ & days & $t=-2.54 ; 0.033$ \\
\hline
\end{tabular}

Table 3: Health indices by gender, $\mathrm{n}=234$

\section{Note: $\mathrm{t}$ stands for t-statistics}

Table 4 shows health indices by income quintile. The poor is less likely to seek medical care compared to the wealthy, $\chi^{2}=22.095$, $\mathrm{P}<0.0001$ ), which is also the case on the number of days having sought medical attention $(\mathrm{F}=2.537, \mathrm{P}=0.042)$. The poor is more likely to be holders of public health insurance than those in wealthier social groups $\left(\chi^{2}=34.410 . \mathrm{P}<0.0001\right)$. Respondents in the middle income categorization spend the most time seeking medical care $(2.1 \pm 2.4$ days) than those in the other income categorizations (Fstatistics $=2.537, \mathrm{P}=0.042$ ); while poor respondents were more likely to use public health care insurance compared to those in more affluent people, which is the reverse in private health insurance coverage.

\begin{tabular}{|c|c|c|c|c|c|c|}
\hline \multirow[t]{3}{*}{ Detail } & \multicolumn{5}{|c|}{ Income quintile } & $x^{2} ; P$ value \\
\hline & 1 & 2 & 3 & 4 & 5 & \multirow[b]{3}{*}{$21.265 ; 0.169$} \\
\hline & $\mathrm{n}(\%)$ & $\mathrm{n}(\%)$ & $\mathrm{n}(\%)$ & $\mathrm{n}(\%)$ & $\mathrm{n}(\%)$ & \\
\hline Self-rated health status & & & & & & \\
\hline Very good & $10(21.9)$ & $3(7.7)$ & $2(4.4)$ & $5(9.4)$ & $4(8.2)$ & \\
\hline Good & $15(32.6)$ & $11(28.2)$ & $11(24.4)$ & $17(32.1)$ & $17(34.7)$ & \\
\hline Fair & $11(23.9)$ & $14(35.9)$ & $19(42.2)$ & $20(37.7)$ & $19(38.8)$ & \\
\hline Poor & $6(13.0)$ & $11(28.2)$ & $10(22.2)$ & $8(15.1)$ & $9(18.4)$ & \\
\hline Very poor & $4(8.7)$ & $0(0.0)$ & $3(6.7)$ & $3(5.7)$ & $0(0.0)$ & \\
\hline Health-care seeking behavior & & & & & & $22.098 ;<0.0001$ \\
\hline Yes & $23(50.0)$ & $29(74.4)$ & $40(88.9)$ & $41(77.4)$ & 41 (83.7) & \\
\hline
\end{tabular}


Citation: Bourne PA, Francis C, Sharpe-Pryce C, Hudson-Davis A, Solan I, et al. (2014) Unspecified Non-communicable Diseases in Jamaica:

Page 6 of 10

\begin{tabular}{|c|c|c|c|c|c|c|}
\hline No & $23(50.0)$ & $10(25.6)$ & $5(11.1)$ & $12(22.6)$ & $8(16.3)$ & \\
\hline Health insurance & & & & & & $34.410 ;<0.0001$ \\
\hline Private & $1(2.1)$ & $1(2.6)$ & $2(4.3)$ & $6(11.3)$ & $14(28.6)$ & \\
\hline Public & $2(4.3)$ & $4(10.3)$ & $4(8.7)$ & $2(3.8)$ & $8(6.3)$ & \\
\hline None & $44(93.6)$ & $34(87.2)$ & $40(87.0)$ & 45 (84.9) & $27(55.1)$ & \\
\hline $\begin{array}{l}\text { No. of visits to health care } \\
\text { practitioner(s) }\end{array}$ & $\begin{array}{l}1.2 \pm 0.5 \text { days; } \\
95 \% \mathrm{Cl}: \quad 1.0 \quad-.1 \\
\text { days }\end{array}$ & 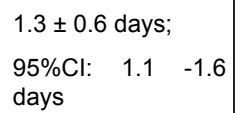 & $\begin{array}{l}2.1 \pm 2.4 \text { days; } \\
95 \% \mathrm{Cl}: 1.3-2.9 \\
\text { days }\end{array}$ & $\begin{array}{l}1.6 \pm 1.1 \text { days } \\
\begin{array}{l}95 \% \mathrm{Cl}: \\
\text { days }\end{array} \quad 1.2 \quad-2.0\end{array}$ & $\begin{array}{l}1.3 \pm 0.5 \text { days; } \\
95 \% \mathrm{Cl}: \\
\begin{array}{lll}\text { days } & 1.1 & -1.5\end{array}\end{array}$ & $\mathrm{~F}=2.537 ; 0.042$ \\
\hline
\end{tabular}

Table 4: Health indices by income quintile, $n=234$

\section{Note: F denotes F-statistics}

Table 5 presents information on comorbidities among the sampled respondents. Apart from having unspecified NCDs, the respondents also indicated that have had infectious diseases such as influenza and diarrhea, and the listed NCDs like chronic repiratory diseases, diabetes and arthritis. Thirty-three ans four tenths percent of the sample indicated having infectious diseases and 66.4 percent have listed NCDs (chronic respiratory, 16.7\%; diabetes, $16.7 \%$ and arthritis, $33.2 \%$ ).
However, none of the respondents indicated having hypertension, with there being no statistical association between gender and typology of diseases $(\chi 2=4.00, \mathrm{P}=0.135)$. In addition to the aforementioned issues, the listed comorbidities were found among the other aged adults and the young old $(\chi 2=1.333, \mathrm{P}=0.503)$. In fact, none of the children, young adults, old elderly and oldest elderly people indicated having the listed NCDs and/or the listed infectious diseases.

\begin{tabular}{|c|c|c|c|c|c|}
\hline \multirow[t]{3}{*}{ Characteristics } & \multicolumn{2}{|c|}{ Gender $^{a}$} & \multicolumn{2}{|l|}{ Age cohort ${ }^{b}$} & \multirow{3}{*}{$\begin{array}{l}\text { Total } \\
\text { N (\%) }\end{array}$} \\
\hline & Male & Female & Other aged adults & Young old & \\
\hline & $\mathrm{N}(\%)$ & $\mathrm{N}(\%)$ & $\mathrm{N}(\%)$ & $\mathrm{N}(\%)$ & \\
\hline \multicolumn{6}{|l|}{ Infectious diseases } \\
\hline Influenza & $1(50.0)$ & $0(0.0)$ & $0(0.0)$ & $1(25.0)$ & $1(16.7)$ \\
\hline Diarrhoea & $0(0.0)$ & $1(25.0)$ & $1(50.0)$ & $0(0.0)$ & $1(16.7)$ \\
\hline \multicolumn{6}{|l|}{ Listed NCDs } \\
\hline Chronic respiratory & $1(50.0)$ & $0(0.0)$ & $(0.0)$ & $1(25.0)$ & $1(16.7)$ \\
\hline Diabetes & $0(0.0)$ & $1(25.0)$ & $(0.0)$ & $1(25.0)$ & $1(16.7)$ \\
\hline Arthritis & $0(0.0)$ & $2(50.0)$ & $1(50.0)$ & $1(25.0)$ & $2(33.2)$ \\
\hline Hypertension & $0(0.0)$ & $0(0.0)$ & $0(0.0)$ & $0(0.0)$ & $0(0.0)$ \\
\hline Total & 2 & 4 & 2 & 4 & 6 \\
\hline
\end{tabular}

Table 5: Comorbidities of sampled respondents, $n=6$

\section{Note: ${ }^{\mathrm{a}} \chi^{2}=4.00, \mathrm{P}=0.135 ;{ }^{\mathrm{b}} \chi^{2}=1.333, \mathrm{P}=0.503$}

Table 6 depicts a binary logistic regression of good self-rated health status by selected sociodemographic variables. Of the selected variables, area of residence and age of respondents account for 17.0 percent (i.e., Nagelkerke $\mathrm{R}^{2}$ ) in the change in good-to-very good selfrated health status of those who indicate having unspecified NCDs. Of the number of respondents in the sample $(n=234), 76.1$ percent were used to establish the regression model (Table 6), and all the factors were determined by a $\mathrm{p}$ value $<0.05$ (i.e., $5 \%$ ). Urban residents with unspecified NCDs are 2.9 times more likely to indicate good-to-very good self-rated health status compared to those who dwell in rural areas $(\mathrm{OR}=2.9,95 \% \mathrm{CI}: 1.187-6.891)$ and age is inversely correlated with good-to-very good self-rated health status $(\mathrm{OR}=0.97,95 \% \mathrm{CI}$ :
0.951-0.999). However, respondents who reside in rural areas statistical have the same good health status as those who dwell in urban zones (i.e., $\mathrm{P}=0.335>0.5$ ). The indirect statistical association between age and good health status denotes that as respondents become older, their good health status decline and vice versa. And rural residents are less likely to report good health status compared to their urban counterparts; but, there is not difference in good health status between those respondents who reside in rural and peri-urban areas. The other variables such as gender, social assistance, marital status, social class, education, social assistance, crowding and income did not influence good health status (i.e., $\mathrm{P}>0.05$ ), which are indicated by the non-purple coloured highlighting. 
Citation: Bourne PA, Francis C, Sharpe-Pryce C, Hudson-Davis A, Solan I, et al. (2014) Unspecified Non-communicable Diseases in Jamaica:

\begin{tabular}{|c|c|c|c|c|c|c|}
\hline Detail & B & Std. Error & $\begin{array}{l}\text { Wald } \\
\text { statistics }\end{array}$ & $P$ value & OR & 95\% C.I. \\
\hline $\begin{array}{l}\begin{array}{l}\text { Social } \\
\text { (1=yes) }\end{array} \\
\text { assistance }\end{array}$ & -1.706 & 1.151 & 2.195 & 0.139 & 0.18 & $0.019-1.735$ \\
\hline Married & 0.117 & 0.435 & 0.073 & 0.788 & 1.12 & $0.480-2.635$ \\
\hline $\begin{array}{l}\text { Divorced, separated } \\
\& \text { widowed }\end{array}$ & -0.292 & 0.806 & 0.131 & 0.717 & 0.75 & $0.154-3.627$ \\
\hline Single & & & & & 1.00 & \\
\hline $\begin{array}{l}\text { Private health } \\
\text { insurance coverage }\end{array}$ & 1.189 & 0.708 & 2.824 & 0.093 & 3.29 & $0.821-13.148$ \\
\hline $\begin{array}{l}\text { Public health } \\
\text { insurance coverage }\end{array}$ & -0.101 & 0.672 & 0.023 & 0.880 & 0.90 & $0.242-3.373$ \\
\hline \multicolumn{7}{|l|}{$\begin{array}{l}\text { No health insurance } \\
\text { coverage }\end{array}$} \\
\hline Secondary & -0.777 & 0.881 & 0.777 & 0.378 & 0.46 & $0.082-2.587$ \\
\hline Tertiary & -0.033 & 1.184 & 0.001 & 0.978 & 0.97 & $0.095-9.853$ \\
\hline Primary and below & & & & & 1.00 & \\
\hline Gender $(1=$ male $)$ & 0.335 & 0.377 & 0.790 & 0.374 & 1.40 & $0.668-2.925$ \\
\hline Middle Class & -0.429 & 0.471 & 0.829 & 0.363 & 0.65 & $0.259-1.639$ \\
\hline Wealthy class & -0.593 & 0.611 & 0.942 & 0.332 & 0.55 & $0.167-1.830$ \\
\hline Poor & & & & & 1.00 & \\
\hline Urban areas & 1.051 & 0.449 & 5.489 & 0.019 & 2.86 & $1.187-6.891$ \\
\hline Peri-urban areas & 0.518 & 0.538 & 0.929 & 0.335 & 1.68 & $0.585-4.817$ \\
\hline Rural areas & & & & & 1.00 & \\
\hline Age & -0.026 & 0.012 & 4.322 & 0.038 & 0.97 & $0.951-0.999$ \\
\hline Crowding & 0.076 & 0.078 & 0.949 & 0.330 & 1.08 & $0.926-1.255$ \\
\hline Income & 0.000 & 0.000 & 2.303 & 0.129 & 1.00 & $1.000-1.000$ \\
\hline Constant & 0.255 & 0.734 & 0.121 & 0.728 & 1.29 & \\
\hline
\end{tabular}

Tabe 6: Binary logistic regression of good self-rated health status by selected sociodemographic variables, $\mathrm{n}=178$

Model $\chi^{2}=23.281, \mathrm{P}=0.007$

$-2 \mathrm{LL}=202.85$, Nagelkerke $\mathrm{R}^{2}=0.17$

Hosmer and Lemeshow Test, $\chi^{2}=9.669, \mathrm{P}=0.289$

Overall classification of data $=76.1$ percent

\section{Limitation}

This study employs secondary data and this retards the inclusion of issues that the researchers could have wanted to examine; but, this does not remove the value of the information presented herein.

\section{Discussion}

Globally, most of the human deaths are due to chronic noncommunicable diseases such as stroke, heart diseases, hypertension, diabetes and cancers [15,25]. According to Ferguson et al. [25], 4 in every 5 deaths occur because of cardiovascular diseases and diabetes. With Mathers et al., [4] indicating that 63 percent of total human deaths occur due to NCDs in 2008, the World Health Organization [3] estimated that the majority of deaths happened in low-to-middle income nations (80 percent). In fact, Hospedales et al. [1] charged that the English-speaking Caribbean has the highest prevalence of NCDs in the Americas, and that any research, which seeks to make available more information on these conditions is critical to the management of the NCDs epidemic.

In 2007, the prevalence rate of Jamaicans with unspecified NCDs (26.3 percent) is greater than cases of those with diabetes mellitus (13.8 percent), hypertension (23.1 percent) and arthritis (6.3 percent) $[17,20]$. In fact, there is limited information with regards to the significance of the issue of unspecified NCDs, which makes it increasingly difficult for policy makers, in Jamaica, to institute proper 
management mechanisms and programmes to address this unknown phenomenon. The issue of ignorance of NCDs, in Jamaica and the wider Caribbean region, will erode the efforts of heads of governments in the region to address the matters declared at the 2007 Summit in Trinidad and Tobago on how to address the increasing incidence and prevalence of NCDs in the Region [16]. Bourne et al.'s work [6] is the rationale for this study and not having adequate information about the population with NCDs and its burden to the society is justification of examining the situation urgently. While this study is unable to provide a detailed description as to what constitute unspecified chronic conditions, it unearth information as to who, what, health indices, comorbidity and social determinants for this cohort of people.

The literature provided pertinent information that those with chronic non-communicable diseases are female [26], reside in low-tomiddle income countries [2,3,27], rural residents [6,11], elderly population $[6-8,28,29]$, and that the Caribbean region has the highest rate of deaths due to NCDs in the Americas [1]. In fact, Jamaica is shown to have a high prevalence of hypertension and diabetes, however, to know the types of NCDs will better aid the management of these conditions. A study by Swaby et al., [29] discovered that 30 percent of Jamaicans $30+$ years old had hypertension and between 13-18 percent had diabetes. In 2014 a research by Bourne et al., [6] revealed that 33.3 percent reports having hypertension and 19.9 percent had diabetes, which highlights that inspite of the intervention programmes, they are by enlarge ineffective. The caption of unspecified NCDs in Jamaica is greater than the group with hypertension and diabetes, and policy makers continue to plan for those with NCDs without a thorough knowledge of the cohort.

Those with 'unspecified NCDs' in Jamaica are less than 31 years old and with Bourne et al.'s work [6] showing that comorbidity is higher among those with specified NCDs such as chronic respiratory, diabetes and arthritis, this would suggest that these conditions are the gateway to additional NCDs in later life. In fact, Bourne et al., [6] discovered that 68.2 percent of those with unspecified NCDs have hypertension, which shows more vividly that these young people are or will burden the state resources, health care system, and the risky lifestyle practices will increase NCDs that could lower their quality of life and reduce life expectancy. Young people, therefore, provide critical information on how we can reduce NCDs in later adulthood and they are the key to the development of effective health intervention programmes geared toward managing NCDs [19]. A recent study shows that effective management and implementation of the right programmes for NCDs can reduce the death rates [30], which explains the rationale for managing these conditions and more importantly knowing what, who, where and everything about the people and their diseases.

There is a clear rationale for the immediate planning of health programmes and interventions for those with NCDs and with the information as evidenced by this study, that this should be a 'race against time' as previously stated by Leeder et al. [31]. The reality is, for decades the Caribbean region, particularly Jamaica, Trinidad and Tobago, and Barbados have been implementing measures to address the NCDs epidemic, which to some extent have been ineffective because of the continued rise in these conditions among the population. Burroughs and colleagues' perspective aptly explained the reasons the Caribbean region has failed to effectively manage the NCDs epidemic. They opined that "The quality and geographic distribution of the published literature on the prevalence of hypertension in Latin America and the Caribbean are inadequate.
Research resources and efforts should be directed in the future toward closing this gap" [32], which is the baseline for this research. Jamaicans who are identified as having unspecified NCDs are portrayed by their socio-demographic characteristics, health indices and social determinant of health. Despite this research, there is still a gap in the knowledge because these diseases are classified as unspecified NCDs, which offers little assistance for health planning, intervention and effective management mechanisms.

For decades, the planning agency in Jamaica has been collecting data on NCDs. The instrument which is used to collect the data on the conditions of illnesses provides data on NCDs such as hypertension, arthritis, diabetes and other NCDs [17]. Initially the other NCDs were much smaller, when compared to hypertension, diabetes and arthritis; but the reality is, the unspecified NCDs have surpassed those, which are stated and now the need arises for the disaggregation of this categorization. Another justification for the disaggregation of the unspecified NCDs is based on the statistics of the ten leading causes of death among Jamaicans. These are external causes (i.e., assault), cerebrovascular diseases, diabetes mellitus, hypertension, neoplasm, heart diseases, chronic lower respiratory diseases and human immunodeficiency virus [18]. However, the Planning Institute of Jamaica and the Statistical Institute of Jamaica only isolate hypertension, diabetes, and arthrtis, when other non-communicable conditions are featured more prominently in leading causes of death. The reality is, the prevalence rate of those with unspecified NCDs are greater than those in the listed categorization, and planning with this ignorance will only foster the continuation of the increase of NCDs. Therefore, not only is there a need to move NCDs to the forefront of health policy planning in Latin America and the Caribbean region [33]; but the need to provide data on all NCDs and move away from using the generic label of 'unspecified NCDs' or other NCDs and properly identify them, as this group has surpassed the listed NCDs in Jamaica. Our rationale for the need to unravel the unspecified NCDs are intricately enveloped in this perspective offered by Ferguson et al., that "Jamaica has the highest scores with regards to the implementation of the targets of the Port-of-Spain Declaration when compared to other countries in the Caribbean region. However, the adequacy and effectiveness of these interventions at the level of disease prevention or risk factor reduction is yet to be determined" [25]. The aforementioned perspective is not totally correct as we are able to use prevalence of NCDs as well as the unspecified NCDs over the last decade to evaluate the effectiveness (or ineffectiveness) of the initiatives.

In 2011 according to Ferguson "We have shown that NCDs remain a major problem in the Caribbean region and that despite a fairly robust policy response in Jamaica, the burden of CNCD risk factors appears to be increasing" [25]. The reality is, there has been a steady increase in NCDs including the unspecified NCDs in Jamaica and it is safe to postulate that the implemented programmes that were meant to curb the rise in these diseases have been ineffective in lowering the prevalence of NCDs. Among the rationales for the aforementioned postulation is embedded in a Summit on NCDs in the Caribbean, Port of Spain, Trinidad in 2007 to address the rising NCDs epidemic in the Caribbean region [34]. It follows, therefore, that all the information on NCDs must be had by policy makers and at the moment this is not the case in Jamaica. With Augustine [16], Eldemire-Shearer et al. [28], Pan American Health Organization/Caribbean Community [35] indicating that NCDs such as diabetes, heart diseases (ischaemic and other) and stroke are the focal causes of mortality in the Caribbean as well as statistics on deaths in Jamaica showed that cerebrovascular diseases, 
cancers, heart diseases, diabetes, and hypertension being among the top ten leading causes of death. Therefore, Jamaican policy makers who only provided and isolated data on diabetes, hypertension and arthritis would be ill-equipped for the broader range of NCDs affecting the population annually.

The prevalence of the unspecified NCDs (or other noncommunicable diseases) is a large category in Jamaica, which is equally the case globally that cannot be disregarded for much longer and warrants disaggregation. In 2008, the WHO [3] indicated that 16 percent of human deaths are caused by Other NCDs compared to 21 percent for cancers, 12 percent for respiratory conditions, 4 percent for diabetes and 48 percent for cardiovascular conditions, with the unspecified categorization being a significant larger than the stated NCDs such as chronic respiratory conditions and diabetes; yet it is treated like an immaterial group. Globally, cardiovascular diseases (i.e., stroke, hypertension and ischaemic heart diseases), cancers, chronic respiratory conditions and diabetes are major concerns, accounting for the majority of human deaths, with the Caribbean being the worst affected in the Americas; however, Jamaica's specified data collection excluded stroke, cancers, and ischaemic heart diseases. Statistics that are published on deaths, by all the aforementioned classifications and morbidity, are truncated into unspecified conditions outside of chronic respiratory, diabetes, hypertension and arthritis; although death caused by arthritis is not among the leading cause of death or concern.

The reality is, using data from the Demographic Statistics for 2008 [18], the researchers computed that 24.2 percent of all human deaths in Jamaica are caused by ischaemic heart disease, cancers, chronic respiratory and cerebrascular diseases (male, 24.9 percent; female, 28.1 percent) compared to 16.8 percent caused by diabetes and hypertension (male, 12.1 percent; female, 22.6 percent). Similar to the mortality statistics, morbidities in the former group are greater than the latter group; however, statistics on self-reported morbidities only separate diabetes, chronic respiratory conditions, hypertension and arthritis, and not ischaemic heart disease, cerebrovascular diseases and cancers, referring to them as unspecified (or Other) chronic conditions. In Jamaica as well as the wider Caribbean region cerebrovascular diseases, cancers, chronic respiratory diseases, ischaemic heart and other heart diseases, and diabetes account for the majority of humans deaths [16]; yet self-reported health matters and other socio-economic issues are published on chronic respiratory, hypertension, arthritis and diabetes with the other conditions labeled as unspecified conditions inspite of the comparable prevalence rates.

The lived reality of those with unspecified chronic diseases are as they become older, their good health status decreases and those with good health status are least likely to reside in rural areas. A plethora of studies on social determinants of health are in the literature; [36-46] however, none showed two social determinants of health of those with unspecified NCDs except the present one. Even studies in Jamaica, as well as one in Barbados, on the population and sub-populations showed many social determinants of health [36-40,46]. Using good health status to examine the social determinants of health, Bourne found that many factors explained health status of the population over their life course including age and area of residence.

Those with unspecified non-communicable diseases in Jamaica are different from the rest of the population and other sub-populations as only two social determinants (i.e., age and area of residence) emerged as explanations of health status. Nevertheless, it concurs with the literature that rural Jamaicans have the least good self-rated health status $[10,11,22,23]$, and that urban Jamaicans who indicated having unspecified NCDs are almost 3 times more likely to report good health status than rural dwellers. Within this realism, the differences in this sub-population must be separately planned for and this justifies the rationale for disaggregating the unspecified chronic categorization.

\section{Conclusion}

Globally, Non-communicable Diseases (NCDs) are a significant public health concern. These diseases are the primary cause of deaths and disabilities in many countries and will only increase if appropriate actions are not taken. There is a lack of adequate data on self-reported unspecified (or other) NCDs, especially in Jamaica and other developing nations, as evidenced by the current study. Even among those with unspecified NCDs, there is evidence that they have chronic respiratory diseases, diabetes and arthritis, which denotes that they cannot be left on the sideline in studies of NCDs.

People who are labeled as having unspecified NCDs are mostly less than 31 years old, utilize public health care facilities and have at most fair self-rated health. This makes health issues on those with unspecified NCDs of even more important and therefore warrants more empirical enquiry. Policy makers will be best served if they are provided with the right information in order to take appropriate actions. Despite the limitations in the literature, this study is timely and provides the framework for a better understanding of unspecified chronic conditions and the impact on public health and health care resources well as demonstrated pertinent information and insight into this cohort. Furthermore, it highlights the ineffectiveness of interventions or policies that have been implemented in the past because of the lack of relevant information. The results from the current study provide considerable evidence and there is rationale for policy makers and government offices to make greater efforts to take actions that are executable and sustainable.

\section{References}

1. Hospedales CJ, Samuels TA, Cummings R, Gollop G, Greene E (2011) Raising the priority of chronic noncommunicable diseases in the Caribbean. Rev Panam Salud Publica 30: 393-400.

2. World Health Organization (2005) Preventing Chronic Diseases a vital investment. Geneva: WHO.

3. World Health Organization (2008) Global Burden of Disease 2004 Update. Geneva: WHO.

4. Mathers CD, Boerma T, Ma Fat D (2009) Global and regional causes of death. Br Med Bull 92: 7-32.

5. Hennis AJ, Fraser HS, Jonnalagadda R, Fuller J, Chaturvedi N (2004) Explanations for the high risk of diabetes-related amputation in a Caribbean population of black african descent and potential for prevention. Diabetes Care 27: 2636-2641.

6. Bourne PA, Francis C, Sharpe-Pryce C, Davis AH, Solan I (2014) Diabetes, Hypertension, Arthritis and Other Chronic Noncommunicable Diseases in an English-speaking Caribbean Nation: A Health Perspective. J Endocrinol Diab 1: 12.

7. Bourne PA, McDaniel S, Williams MS, Francis C, Kerr-Campbell MD, et al. (2010) The changing faces of diabetes, hypertension and arthritis in a Caribbean population. N Am J Med Sci 2: 221-229.

8. Bourne PA, Charles CAD (2011) Hypertensive And Modeling Their Social Determinants Of Self-Rated Health Status In A Middle-Income Developing Nation. J Clin Diagn Res 5: 1-8.

9. Bourne PA (2012) Health of children in Jamaica: the new health realities. Indian J Med Sci 66: 175-188. 
10. Bourne PA (2013) Chronic Diseases, Self-Rated Health Status, Health Care Utilization and Health Insurance Status of Males in a Caribbean nation. J Behav Health 2: 66-78.

11. Wilks R, Younger N, Tulloch-Reid M, McFarlane S, Francis D (2008) Jamaica health and lifestyle survey 2007-8. Technical report. Kingston Epidemiology Research Unit, Tropical Medicine Research Institute, University of the West Indies, Mona.

12. James J, Soyibo AK, Hurlock L, Gordon-Strachan G, Barton EN (2012) Cardiovascular Risk Factors in an Eastern Caribbean Island: Prevalence of Non-communicable Chronic Diseases and Associated Lifestyle Risk Factors for Cardiovascular Morbidity and Mortality in the British Virgin Islands. West Indian Med J 61: 429-436.

13. Echouffo-Tcheugui JB, Kengne AP (2011) Chronic non-communicable diseases in Cameroon - burden, determinants and current policies. Global Health 7: 44

14. Mayosi BM, Flisher AJ, Lalloo UG, Sitas F, Tollman SM, et al. (2009) The burden of noncommunicable diseases in South Africa. Lancet 374: 934-447.

15. World Health Organization (2011) Global Status Report on Noncommunicable Diseases 2010. Geneva.

16. Augustine S (2007) Facing the challenge of the CNCD epidemic: The global situation and Caribbean perspective. WHO.

17. Planning Institute of Jamaica (1990-2010), Statistical Institute of Jamaica. Jamaica Survey of Living Conditions, 1989-2009. Kingston: PIOJ STATIN.

18. Statistical Institute of Jamaica (1971-2013) Demographic statistics, 1970-2012. Kingston: Statistical Insitute of Jamaica.

19. Baldwin W, Kaneda T, Amato L, Nolan L (2013) Noncommunicable diseases and youth: A critical window of opportunity for Latin America and Caribbean. Washington: The Population Reference Bureau.

20. Statistical Institute Of Jamaica (2008) Jamaica Survey of Living Conditions, 2007 [Computer file]. Kingston, Jamaica: Statistical Institute Of Jamaica [producer], 2007. Kingston, Jamaica: Planning Institute of Jamaica and Derek Gordon Databank, University of the West Indies.

21. World Bank (2002) Poverty and Human Resources. Jamaica Survey of Living Conditions, 1988-2000. Basic information. Washington: The World Bank.

22. Bourne PA (2008) Medical sociology: modelling well-being for elderly people in Jamaica. West Indian Med J 57: 596-604.

23. Boume PA, McGrowder DA (2009) Health status of patients with selfreported chronic diseases in Jamaica. N Am J Med Sci 1: 356-364.

24. Shao R (2012) Chronic diseases and health promotion. Geneva: World Health Organization.

25. Ferguson TS, Tulloch-Reid MK, Cunningham-Myrie CA, DavidsonSadler T, Copeland S, et al. (2011) Chronic disease in the Caribbean: strategies to respond to the public health challenge in the region. What can we learn from Jamaica's experience? West Indian Med J 60: 397-411.

26. United Nations (2010) Global Strategy for Women's and Children's Health. New York: United Nations.

27. Epping-Jordan JE, Galea G, Tukuitonga C, Beaglehole R (2005) Preventing chronic diseases: taking stepwise action. Lancet 366: 1667-1671.

28. Eldemire-Shearer D, James K, Morris C, Holder-Nevins D, Lawes H, et al. (2011) Chronic disease and ageing in the Caribbean: opportunities knock at the door. West Indian Med J 60: 471-477.
29. Swaby P, Wilson E, Swaby S, Sue-Ho R, Pierre R (2001) Chronic diseases management in the Jamaican setting: HOPE worldwide Jamaica's experience. P N G Med J 44: 171-175.

30. Yamada T, Chen CC, Chiu IM, Rizvi SW (2013) Non-Communicable Diseases in Developing Countries: Causes and Health Policy/Program Assessments. J Trop Dis 1: 117.

31. Leeder S, Raymond S, Greenberg H, Liu H, Esson K (2004) A Race Against Time. The Challenge of Cardiovascular Disease in Developing Countries. The Centre for Global Health and Economic Development.

32. Burroughs Peña MS, Mendes Abdala CV, Silva LC, Ordúñez P (2012) Usefulness for surveillance of hypertension prevalence studies in Latin America and the Caribbean: the past 10 years. Rev Panam Salud Publica 32: $15-21$.

33. Glassman A, Gaziano TA, Bouillon Buendia CP, Guanais de Aguiar FC (2010) Confronting the chronic disease burden in Latin America and the Caribbean. Health Aff (Millwood) 29: 2142-2148.

34. CARICOM Secretariat (2007) Communiqué issued at the conclusion of the regional summit of heads of government of the Caribbean Community (CARICOM) on chronic non-communicable diseases (NCDS). Port-of-Spain: Trinidad and Tobago.

35. Pan American Health Organization/Caribbean Community (2006) Report of the Caribbean Commission on Health and Development.

36. Bourne PA (2009) Social determinants of self-evaluated good health status of rural men in Jamaica. Rural Remote Health 9: 1280.

37. Bourne PA (2008) Health determinants: using secondary data to model predictors of well-being of Jamaicans. West Indian Med J 57: 476-481.

38. Bourne PA (2009) Social determinants of health in Jamaica: Are there differences between the sexes and are of residence? HealthMed Journal 3: 359-373.

39. Bourne PA, Eldemire-Shearer D (2010) Difference in social determinants of health between men in the poor and the wealthy social strata in a Caribbean nation. N Am J Med Sci 2: 267-275.

40. Bourne PA (2010) Modelling social determinants of self-evaluated health of poor old people in a middle-income developing nation. J Biomedical Sci and Engineering 3: 700-710.

41. Grossman M (1972) The demand for health- a theoretical and empirical investigation. New York: National Bureau of Economic Research.

42. Smith JP, Kington R (1997) Demographic and economic correlates of health in old age. Demography 34: 159-170.

43. Kelly M, Morgan A, Bonnefog J, Beth J, Bergmer V (2007) The Social Determinants of Health: developing Evidence Base for Political Action, WHO Final Report to the Commission.

44. Solar O, Irwin A (2007) A Conceptual Framework for Analysis and Action on the Social Determinants of Health. WHO.

45. Graham H (2004) Social determinants and their unequal distribution: clarifying policy understandings. Milbank Q 82: 101-124.

46. Hambleton IR, Clarke K, Broome HL, Fraser HS, Brathwaite F, et al. (2005) Historical and current predictors of self-reported health status among elderly persons in Barbados. Rev Panam Salud Publica 17: 342-352. 